\title{
Trend of Research on Role of Nurses Working in Nursery Schools
}

\author{
Keiko Sakou, ${ }^{1}$ Chieko Akuzawa, ${ }^{2}$ Chiharu Aoyagi, ${ }^{2}$ \\ Takatoshi Makino ${ }^{1}$ and Shiomi Kanaizumi ${ }^{1}$
}

\begin{abstract}
Purpose : The objectives of this paper were to review previous studies about the roles of nurses who work in nursery schools, and to identify research trends and issues that need to be addressed. Methods : Searching Japanese references from 1990 to 2010 in Japana Centra Revuo Medicina Web, Ver.4 and Citation Information by National Institute of Informatics (CiNii) using keywords "nursery school," "nurse," and "role," this study explored the current practice conditions and roles of nurses working at nursery schools. Results : Twenty seven articles were retrieved for analysis, of which more than $70 \%$ reported results of quantitative research. Studies about directors and managers constituted $34.2 \%$ of the articles, and those about nurses, $28.9 \%$. This study identified current nurse practice conditions in nursery schools and the roles and duties expected of nurses by nursery school administrators, managers, and parents. In addition, nursery school nurses identified some limitations and restrictions placed on their nursing and health activities, while they expressed desires to more broadly exercise their professional skills. Discussion : In order to promote health and safety of children in nursery schools and improve the assignment of nursery school nurses, it is necessary to understand the current conditions and issues of nursing practice and health care, as well as an empirically grounded analysis of support for these nurses. (Kitakanto Med J 2011;61:387 394)
\end{abstract}

Key words : Nursery school, nurse, role

\section{Introduction}

There are two functions that society expects nursery schools to fulfill : caring for children well and providing childrearing support. ${ }^{1}$ This is because concerns about various social problems have been raised as a result of recent dramatic changes in the social environment following urbanization, trends toward the nuclear family, and a declining birthrate. Trends toward urbanization and the nuclear family have been implicated as causes of weakened interpersonal relationships in local communities. Lack of social companionship and mutual support in neighborhoods, along with fewer opportunities to receive grandparents' childrearing wisdom, have tended to isolate families with children. Due to declining birthrates, children often end up with few playmates in their local commu- nity and few sibling relationships at home, which lead to reduced opportunities to acquire valuable social skills. These changes in the social environment around children and parents only exacerbate the problem of a "declining ability to raise children" in the family and the local community. Given these conditions, expectations for nursery schools to provide greater levels of childrearing support have risen. People also expect that children in nursery schools will be well taken care of based on the idea that maintaining their life, health, and safety is of paramount importance: that is their job. In addition, the number of children with chronic illnesses, disorders, and allergies has been increasing in recent years. ${ }^{2}$ Given the current economic recession, more parents request nursery school care even when their children are sick, which raises the expectation that nurses will take care of

1 Gunma University Graduate School of Health Sciences, 3-39-22 Showa-machi, Maebashi, Gunma 371-8514, Japan 2 Doctoral program (mater's course), Gunma University Graduate School of Health Sciences, 3-39-22 Showa-machi, Maebashi, Gunma 371-8514, Japan

Received: April 18, 2011

Address: KEIKO SAKOU Gunma University Graduate School of Health Sciences, 3-39-22 Showa-machi, Maebashi, Gunma 371-8514, Japan 
children during and after an illness. ${ }^{3,4}$ In addition, the roles of nursery school nurses have diversified because of many new challenges to the health and safety of children, including infectious diseases, SIDS, and accident prevention and detection measures., ${ }^{5,6}$ Nursery health care is defined as a practice to ensure children's well being, and is an important component of health maintenance for mothers and children. Nurses working at nursery schools play a central role in fulfilling these tasks. ${ }^{7}$

Under these social circumstances, the 2008 Child Health and Nursery School Guidelines were issued as the 3rd revised version since 1965 when the guidelines were first enacted. ${ }^{8}$ Previous nursery school guidelines had merely been "notifications" from a bureau of the Ministry of Health, Labour and Welfare, which did not have legally binding effects. However, the latest revised guidelines were enacted in accordance with a Ministerial notice, which is an ordinance with legal requirements (socialresponsibility) that expand the binding, restricting, and regulating effects. The latest revision specifically describes the diversified functions and roles of each professional at nursery schools, and matches ongoing larger changes in assignments and roles of nursery school nurses as professionals of child health care. Following the revision of the Child Health and Nursery School Guidelines, a 5-year-long "Action Program" from 2008 to 2012 was announced by the Ministry of Health, Labour and Welfare. ${ }^{9}$ This program involves the "Promotion of Securing Professional Staff Including Nurses," indicating that the national government recognizes the need for local government engagement in this issue, and provides support. The revised version of the Child Health and Nursery School Guidelines and the "Action Program" together are expected to change the assignments and roles of nursery schools nurses significantly.

Against this background, this study conducted a literature review, looking at previous studies in the past two decades of the roles of nurses at nursery schools in Japan, with the objective of examining trends of research on the practices and roles of these nurses, and to identify research trends and issues that need to be addressed.

\section{Study Objectives}

The objectives of this study were to examine trends of research on nursery school nursing practice, and to identify issues that need to be addressed in future research. This will help provide insights into practice improvement as nurses fully exercise their professional skills in order to ensure children's health and safety.

\section{Definition of Nursery School Nurses}

In this study, nursery school nurses are operationally defined as "workers who have acquired a license of a nurse, health nurse, midwife, or assistant nurse, and who work in a nursery school."

\section{Methods}

\section{Study Subjects}

This study examined articles published in Japana Centra Revuo Medicina Web, Ver.4 and Citation Information by National Institute of Informatics (CiNii) from 1990-when the first revision of Child Health and Nursery School Guidelines was issuedthrough 2010. Among 42 articles retrieved using the keywords "nursery school," "nurse," and "role," 27 articles that were relevant to this study and available were selected for final analysis. Because foreign countries have their own systems and standards regarding nursery schools, this study included no foreign studies or literature, and focused solely on the Japanese experience.

\section{Analysis}

A literature review form was created for data collection and subsequent analysis. Articles were chronologically listed along with journal titles, purposes, subjects, data collection methods, results/discussion, keywords, and summaries. This study identified important issues in the field by organizing articles by subjects such as nursery school nurses, administrators, nursery teachers, and parents. Reliability of the analysis was examined and verified through ongoing discussion with co-researchers.

\section{Results}

\section{Changes in Numbers of References by Year}

Numbers of references by year are shown in Table 1. Chronological reviews around the years of 1990 , 1999, and 2008, when revisions of Child Health and Nursery School Guidelines were made, did not reveal any time-dependent increases or decreases in the numbers of articles. Regarding the disciplines of the authors of the articles, 17 articles were in Nursing and Health Sciences, six in Sociology, three in Social Welfare, and one in Medicine. As for study subjects, 11 articles studied nurses, 13 studied nursery school administrators, six studied nursery teachers, and eight studied parents (including multiple subjects).

\section{Analysis of Article Contents (Table 2)}

The contents of articles were sorted into the following categories: (1) current conditions of childcare and nursery school health, and issues to be addressed, 
Table 1 Chronological Changes of Studies by Category

\begin{tabular}{|c|c|c|c|c|c|c|c|c|c|c|c|c|c|c|c|c|c|c|c|}
\hline & \multirow{2}{*}{ Numbers of Studies by Year } & No. & $\%$ & 1996 & 1997 & 1998 & 1999 & 2000 & 2001 & 2002 & 2003 & 2004 & 2005 & 2006 & 2007 & 2008 & 2009 & 201 & 10 \\
\hline & & 27 & 100 & 2 & 1 & 2 & 1 & 3 & 3 & 1 & 1 & 0 & 0 & 2 & 3 & 2 & 4 & & 2 \\
\hline \multirow[t]{4}{*}{ 1. Type of Study } & 1. Qualitative & 5 & 18.5 & 0 & 0 & 0 & 1 & 0 & 0 & 1 & 0 & 0 & 0 & 1 & 1 & 0 & 0 & & 1 \\
\hline & 2. Quantitative & 17 & 63.0 & 2 & 1 & 2 & 0 & 3 & 2 & 0 & 1 & 0 & 0 & 0 & 1 & 2 & 2 & & 1 \\
\hline & 3. Both & 5 & 18.5 & 0 & 0 & 0 & 0 & 0 & 1 & 0 & 0 & 0 & 0 & 1. & 1 & 0 & 2 & & 0 \\
\hline & Total Number & 27 & 100.0 & 2 & 1 & 2 & 1 & 3 & 3 & 1 & 1 & 0 & 0 & 2 & 3 & 2 & 4 & & 2 \\
\hline \multirow[t]{5}{*}{ 2. Research Design } & 1. Exploratory Factor Analysis & 10 & 31.3 & 0 & 0 & 0 & 1 & 0 & 1 & 1 & 0 & 0 & 0 & 2 & 2 & 0 & 2 & & 1 \\
\hline & 2. Correlation Analysis & 21 & 65.6 & 2 & 1 & 2 & 0 & 3 & 3 & 0 & 1 & 0 & 0 & 1 & 2 & 2 & 4 & & 1 \\
\hline & 3. Association Examination & 1 & 3.1 & 0 & 0 & 0 & 0 & 0 & 0 & 0 & 0 & 0 & 0 & 0 & 0 & 0 & 0 & & 0 \\
\hline & 4. Causal Hypothesis Examination & 0 & 0.0 & 0 & 0 & 0 & 0 & 0 & 0 & 0 & 0 & 0 & 0 & 0 & 0 & 0 & 0 & & 0 \\
\hline & Multiple Responses & 32 & 100.0 & 2 & 1 & 2 & 1 & 3 & 4 & 1 & 1 & 0 & 0 & 3 & 4 & 2 & 6 & & 2 \\
\hline \multirow[t]{6}{*}{ 3. Data Collection } & 1. Questionnaire (Existing Scales) & 0 & 0.0 & 0 & 0 & 0 & 0 & 0 & 0 & 0 & 0 & 0 & 0 & 0 & 0 & 0 & 0 & & 0 \\
\hline & 2. Questionnaire (Original) & 24 & 85.7 & 2 & 1 & 2 & 1 & 3 & 3 & 1 & 1 & 0 & 0 & 1 & 3 & 2 & 4 & & 0 \\
\hline & 3. Interview & 3 & 10.7 & 0 & 0 & 0 & 0 & 0 & 0 & 0 & 0 & 0 & 0 & 1 & 1 & 0 & 0 & & 1 \\
\hline & 4. Observation & 0 & 0.0 & 0 & 0 & 0 & 0 & 0 & 0 & 0 & 0 & 0 & 0 & 0 & 0 & 0 & 0 & & 0 \\
\hline & 5. Other & 1 & 3.6 & 0 & 0 & 0 & 0 & 0 & 0 & 0 & 0 & 0 & 0 & 0 & 0 & 0 & 0 & & 1. \\
\hline & Multiple Responses & 28 & 100.0 & 2 & 1 & 2 & 1 & 3 & 3 & 1 & 1 & 0 & 0 & 2 & 4 & 2 & 4 & & 2 \\
\hline \multirow[t]{5}{*}{ 4. Analysis } & 1. Descriptive Statistics & 15 & 50.0 & 2 & 1 & 2 & 0 & 2 & 3 & 0 & 0 & 0 & 0 & 0 & 1 & 1 & 2 & & 1 \\
\hline & 2. Inferential Statistics & 7 & 23.3 & 0 & 0 & 0 & 0 & 1 & 0 & 0 & 1 & 0 & 0 & 1 & 1 & 1 & 2 & & 0 \\
\hline & 3. Content Analysis & 7 & 23.3 & 0 & 0 & 0 & 1 & 0 & 0 & 0 & 0 & 0 & 0 & 2 & 2 & 0 & & & 1 \\
\hline & 4. Other Qualitative Method & 1 & 3.3 & 0 & 0 & 0 & 0 & 0 & 0 & 1. & 0 & 0 & 0 & 0 & 0 & 0 & 0 & & 0 \\
\hline & Multiple Responses & 30 & 100.0 & 2 & 1 & 2 & 1 & 3 & 3 & 1 & 1 & 0 & 0 & 3 & 4 & 2 & 5 & & 2 \\
\hline \multirow[t]{5}{*}{ 5. Subjects } & 1. Nursery School Nurses & 11 & 28.9 & 0 & 0 & 1 & 0 & 1 & 0 & 0 & 1 & 0 & 0 & 2 & 2 & 1 & & & 1 \\
\hline & 2. Nursery School Administrators & 13 & 34.2 & 1 & 1 & 1 & 0 & 2 & 2 & 0 & 1 & 0 & 0 & 0 & 2 & 1 & & & 0 \\
\hline & 3. Nursery School Teachers & 6 & 15.8 & 1 & 0 & 0 & 0 & 1 & 0 & 0 & 0 & 0 & 0 & 1 & 0 & 0 & 3 & & 0 \\
\hline & 4. Parents & 8 & 21.1 & 1 & 0 & 0 & 1 & 1. & 1 & 1. & 0 & 0 & 0 & 1 & 0 & 0 & & & 1 \\
\hline & Multiple Responses & 38 & 100.0 & 3 & 1 & 2 & 1 & 5 & 3 & 1 & 2 & 0 & 0 & 4 & 4 & 2 & 8 & & 2 \\
\hline \multirow[t]{5}{*}{ 6. Specialization Fields of Researchers } & 1. Nursing and Health Sciences & 17 & 63.0 & 2 & 0 & 1 & 0 & 1 & 1 & 0 & 1 & 0 & 0 & 2 & 2 & 1 & 4 & & 2 \\
\hline & 2. Medicine & 1 & 3.7 & 0 & 0 & 0 & 0 & 0 & 0 & 0 & 0 & 0 & 0 & 1 & 0 & 0 & 0 & & 0 \\
\hline & 3. Sociology & 6 & 22.2 & 0 & 1 & 0 & 1 & 2 & 1 & 1 & 0 & 0 & 0 & 0 & 0 & 0 & 0 & & 0 \\
\hline & 4. Social Welfare & 3 & 11.1 & 0 & 0 & 1 & 0 & 0 & 1. & 0 & 0 & 0 & 0 & 0 & 0 & 1 & 0 & & 0 \\
\hline & Total Number & 27 & 100.0 & 2 & 1 & 2 & 1 & 3 & 3 & 1 & 1 & 0 & 0 & 3 & 2 & 2 & 4 & & 2 \\
\hline
\end{tabular}

(2) nursery school administrators' expectations for nurse responsibilities, (3) nursery teachers' expectations for nurse responsibilities, and (4) parental expectations for nurses. The descriptions that follow are reports of each article by category (numbers in brackets correspond to the articles reviewed).

(1) Current Conditions of Childcare and Nursery School Health, and Issues to be Addressed

Yumome et al. ${ }^{(4)}$ reports that about $40 \%$ of nursery school nurses in their study were also engaged in childcare as nursery school teachers. Similarly, more than $70 \%$ of nurses were observed to provide childcare as teachers in Okamoto et al., ${ }^{(7)} 50 \%$ in Kohno et al., ${ }^{(1)}$ and $80 \%$ in Kimura et al. ${ }^{(15)}$ Murakami et al., ${ }^{22}$ in a study of nursery schools in Tokyo-where more nurses are assigned than in any other areas in Japan-reports that while more than $80 \%$ of nursery schools in their study had assigned nurses, nearly $90 \%$ of nurses were engaged in childcare. From these findings, researchers conclude that there are "unclear role boundaries", (1) "difficulties in fulfilling nurse practice responsibilities due to childcare responsibilities", (15,(21) and "insufficient time to prepare for health education", ${ }^{21}$ which suggest that one issue for nursery school nurses is that they are hindered from fulfilling their professional roles and using their specialized skills. Studies also report nurses perceive difficulties in pursuing their roles due to "insufficient professional knowledge," "unclear role boundaries between nursing practice and childcare," "lack of knowledge about nursery schools," "limited information sources," and "lack of availability of professional consultants in the field of health and medicine" (Inage et al. (19); "little understanding of nursery teachers and parents about health activities" (Kimura et al. $\left.{ }^{(5)}\right)$; and "problems arising in relationships with parents and nursery teachers" (Yano et al. ${ }^{(2)}$ ). Kimura et al. ${ }^{\text {(5) }}$ argues for "the need for nurse assignments free from the responsibilities of childcare, and the need to assign multiple nurses per school," and "the need for collaboration with other agencies and professionals." Kohno et al. ${ }^{(1)}$ also argues that "because nurse involvement in childcare hinders her from pursuing her own professional practice as a nurse, it is essential to keep her free so that she can be flexible in working on health management for the entire nursery school while being based in the nursery office."

These results demonstrate that depending on assignment situations and conditions, nursery school nurses experience role conflict between their "roles as infant-care staff" and "their original roles as nurses to be engaged in health activities." This conflict prevents them from fully pursuing their own professional practice of nursing. The results also demonstrate the current conditions of nurses where they were unable to pursue their own professional roles due to unclear role boundaries at particular sites, and where some have only limited opportunities to deepen their professional knowledge because of a lack of collaboration with other professionals.

(2) Nursery School Administrators' Expectations for Nurse Roles

The proportions of nursery schools with assigned nurses are reported as $15.2 \%$ in Nagasaki prefecture in 1996 (the oldest record), ${ }^{2} 17.7 \%$ nationwide in $2000,{ }^{8}$ and $22.5 \%$ nationwide in $2001,{ }^{112}$ all of which average out to around $20 \%$. Assignment rates have been slightly increasing since the 3 rd revision of Child 


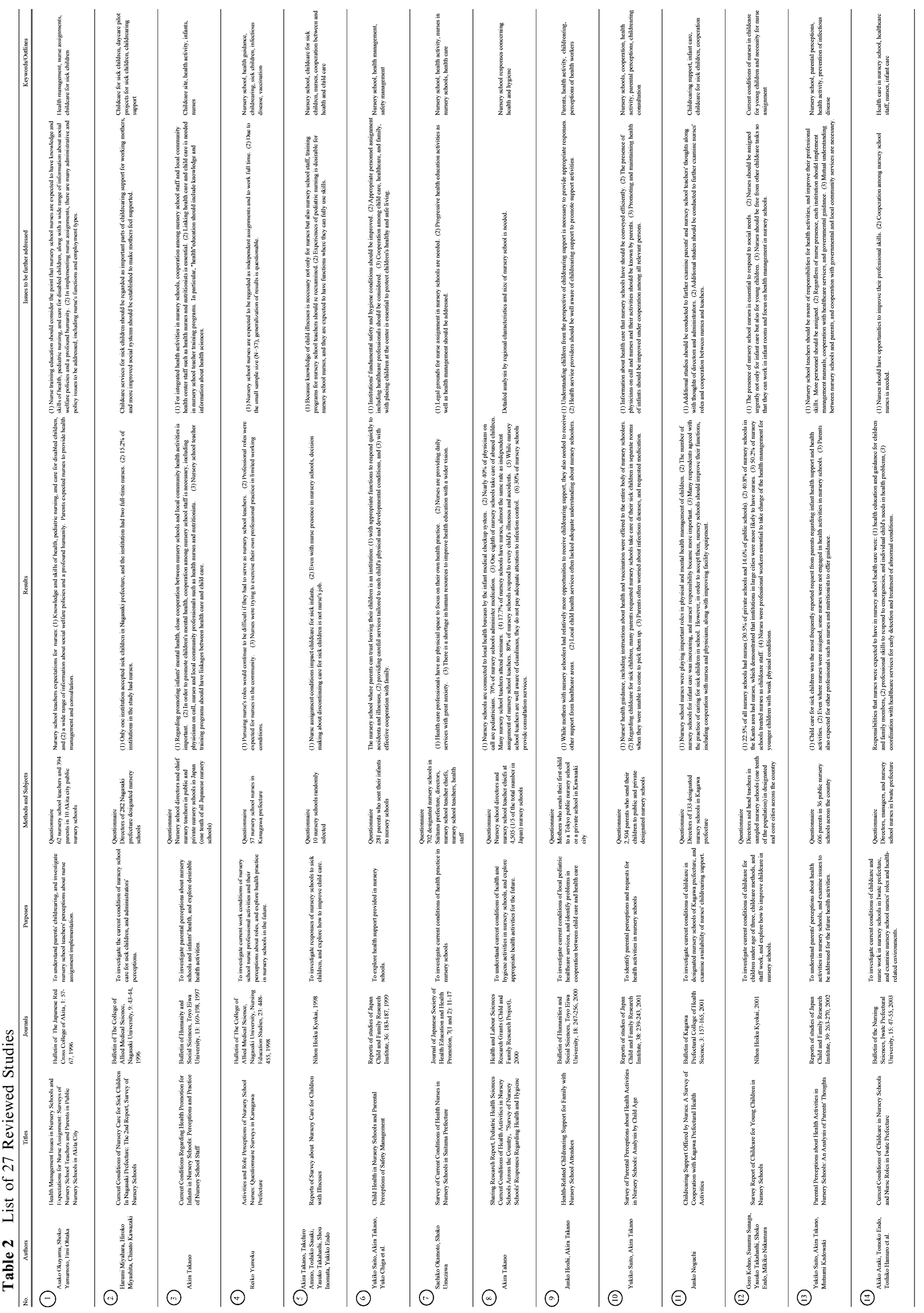




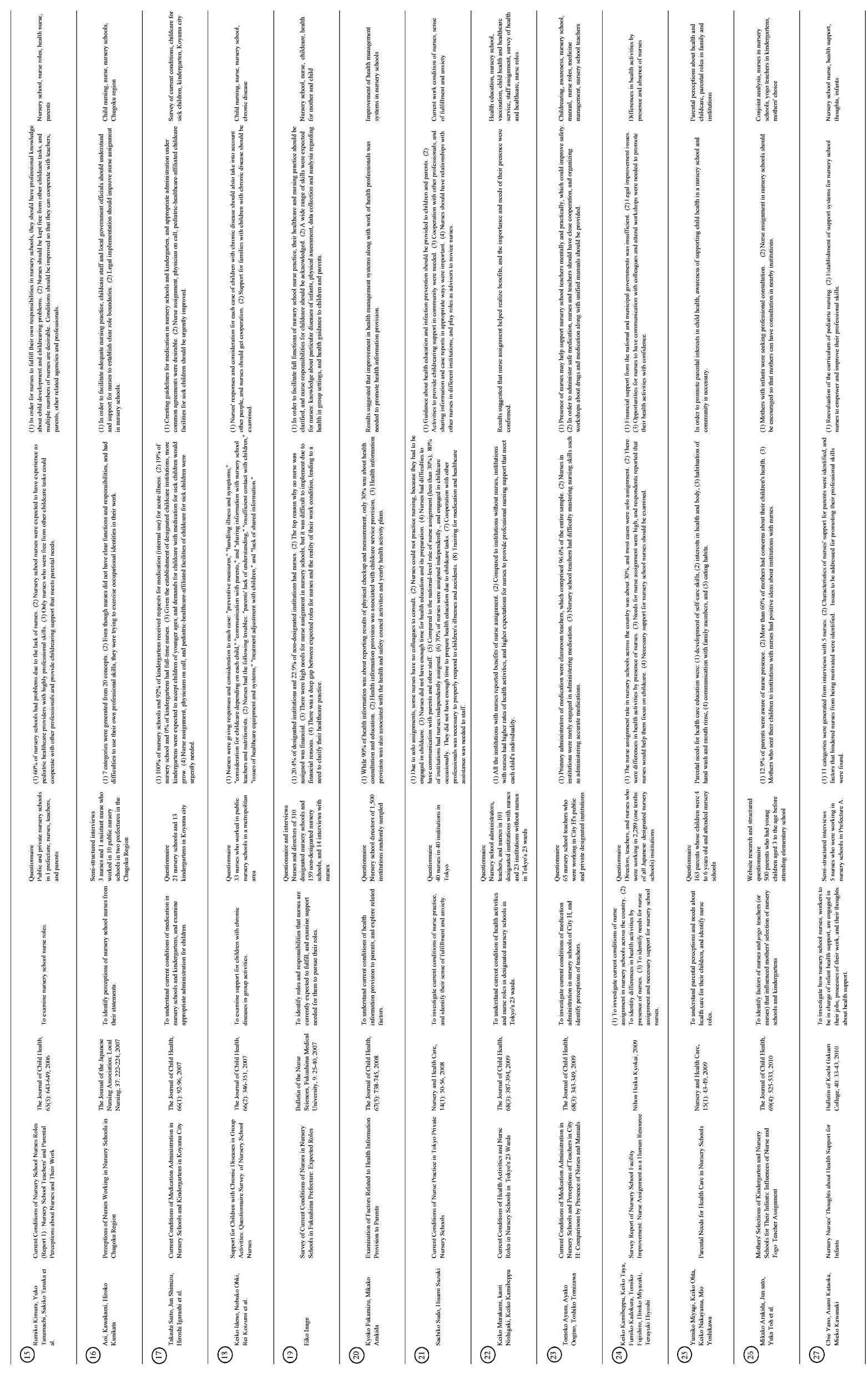


Health and Nursery School Guidelines in 2008: $37.9 \%$ in City $\mathrm{H}$ in $2009,{ }^{3}$ and $29.7 \%$ across the whole country in 2009. Nursery schools in and around Tokyo, where nurse assignments have been most prevalent, have higher rates: $50.2 \%$ in major, core, and other cities in 2008, ${ }^{\text {(2) }}$ and $81.5 \%$ in Tokyo's 23 wards in 2009. 22. Reasons for not having assigned nurses were reported as follows : limited budgets for personnel costs and other financial issues, lack of requests from sites, local government indifference, and small populations of children under the age of one.(1),(1) According to the finding of Kamibeppu et al., ${ }^{24}$ 80\% of nursery professionals acknowledged the importance of having assigned nurses in nursery schools. Araki et al. (14) also reports that around $90 \%$ of directors and administrators wanted to have nurses assigned to their institutions. In addition, more than $60 \%$ of nursery schools reported that they experienced inconveniences due to the absence of nurse, such as: "child accidents and illnesses," difficulties with "child health management and guidance," a shortage of "preventive measures against mass infection," and unclear "handling and decision making concerning sick children". (14,(2) Directors and administrators had diverse expectations for nurses: "health guidance, safety management/ instruction for children and parents," "advice and guidance about health for nursery teachers," "daily observation of children concerning their health," "handling and decision making concerning children's changes of health conditions," and running "first aid and cardiopulmonary resuscitation workshops". (7),8

These findings demonstrate that nursery school administrators expected nurses to be in charge of maintaining children's health and safety, which clarifies that they were keenly aware of the urgent need to have assigned nurses. In reality, however, wider implementation of an assigned nurse in every nursery school is difficult due to financial reasons, including limited budgets for personnel. While nursery school nurses were regarded in the past as nursery staff providing infant care, they are now expected to be generalist health-management professionals, not strictly limited to taking care of infants and sick children. Thus, the need to start building a foundation for greater levels of assigned nurses is becoming evident.

\section{(3) Nursery School Teachers' Expectations for Nurse Roles}

Okuyama et al. ${ }^{1}$ reports that $90 \%$ of nursery school teachers hoped to have nurses assigned to their schools. Other current studies of nursery school teachers also report deficiencies, including a lack of medical knowledge and insufficient time for children's health management due to their busy work schedules, and a "lack of space to take care for other children if one child is sick," and "no professional consultations available about health", (1),(7), (5) The frequency of taking care of children with chronic diseases or health conditions has been increasing, which leads to situations where nursery school teachers have to administer medication that is more properly handled by healthcare professionals. Cases of improper medication administration were reported, such as "forgetting to administer medication," and "failures to administer due to spilling medication or child being asleep". ${ }^{3}$ Many nursery school teachers reported a desire to have nurses in nursery schools, and reported that nursery schools with nurses should accept requests for medication administration, which should be handled by the nurses. ${ }^{3}$ According to the finding of Kamibeppu et al., ${ }^{24}$ while there were many nursery school teachers who thought that they would "be able to focus on childcare" by leaving healthcare routines to nurses, others opposed the idea of assigning nurses just for healthcare work, asserting that "more nursery school teachers need to be hired than nurses," "nurses should also be engaged in nursery practice," and "not full-time but part-time employment is enough." In addition, some nursery school teachers complained about the capabilities of nurses, such as "inadequate skills regarding medication and medicine management," and providing "unclear advice and instructions about health". (15)

These findings demonstrate that nursery school teachers had high expectations for the roles of nurses. They felt especially strongly about the need for nurses to take care of sick children, but teachers did not necessarily place much importance on the nurses' typical role in health maintenance and management.

\section{(4) Parental Expectations for Nurses}

Nearly half $(46 \%)$ of parental concerns regarding the balance between job and childrearing was "having to take a day off due to child's illness," and more than $60 \%$ of parents hoped nursery schools would "care for their children when they are slightly ill",(1),(6),(10) Kimura et al. ${ }^{(5)}$ also reports that parents had high expectations for nursery school nurses that they would take care of sick children in separate rooms. Parents who had children with health-related concerns such as disorders or chronic disease wished to have someone with whom they could consult. ${ }^{(1,(9)}$ Parents with young children had particularly strong needs related to medical and health care, and many had consultations regarding "discipline," "health conditions and diseases," and "dieting and nutrition," which demonstrated their "anxiety and distress about childrearing" and their desire for professional consultations. ${ }^{(1)}$ Regarding 
assigned nurses in nursery schools, while $60 \%$ of parents hoped for such assignment, ${ }^{(1)}$ and the presence of nurses gave them a great sense of security, ${ }^{(10}$ around $40 \%$ of parents were not exactly aware of the presence of nurses in nursery schools. ${ }^{(15}$

These findings demonstrate that many parents hoped that nurses at nursery schools could take care of their children when they were sick. Parents also hoped that nurses with professional skills would provide consultations and advice about their healthchallenged children and childrearing. These studies also reveal that while many parents hoped for assigned nurses in nursery schools, which promoted a parental sense of security, the presence of nurses was not always acknowledged by all parents.

\section{Discussion}

The first nursery school for infants was opened in Mitaka city in Tokyo in 1956, and such facilities later spread across the country. ${ }^{10}$ The 1969 Guidelines for Designated Nursery Schools for Infants and Staff Assignment stipulated that it was necessary to assign at least one nurse or health nurse in nursery schools where more than nine infants were accepted. However, this stipulation was removed in 1998 through a partial revision of the Child Welfare Act. ${ }^{11}$ Given this historical background, only 20 to $30 \%$ of nursery schools in Japan currently have nurses assigned. Many studies report that parents and nursery school staff strongly assert a desire to have an assigned nurse. Given the recent stipulations about nurse assignment in the Child Health and Nursery School Guidelines and the "Action Program," assigning nurses in nursery schools is assumed to be underway. However, the current condition of nurse assignment is often to place nurses as childcare staff, not solely as nurses. In addition, solo nurse assignments are common, which leads to many difficulties and barriers to pursuing the primary tasks and duties of nurses. ${ }^{12,13}$

In this study which reviewed 27 previous studies about nursery school nurses, there were 11 references that had nurses as study subjects, which was fewer than the number of references that had nursery personnel such as nursery administrators and teachers (19 articles). Of the 11 studies, only five focused solely on nurses. In addition, sample sizes tended to be small, leading to difficulty in generalizing their results. There were only three qualitative studies with nursery school nurses as subjects in this review. Therefore, further studies using qualitative methods as well as quantitative analysis should be conducted to empirically identify factors that could facilitate nurses' fulfilling their own professional aspirations, and then elucidate improvement measures.
In order for nursery school nurses to pursue childcare and healthcare activities while understanding each child's personality, developmental level, and family background, collaborative work with nursery school teachers is essential. Yano et al. ${ }^{20}$ argues for the importance of collaboration between nursery school teachers and nurses along with nurse's tasks in institutions, asserting that the "perspectives of both nursery school teachers and nurses are necessary to promote children's health, and the nurse's job is providing adequate support." Previous studies of nursery school teachers focusing on their expectations for nurses revealed that handling and making decisions about treating sick children were perceived as highly important, but health care duties were not thought to be as important, which showed a gap of perceptions held about nurses. This is possibly because many nursery schools do not have manuals or standards of nurse duties, which makes it difficult for nursery school teachers to understand the decided or original duties of nurses. Recognizing each professional's skills and working cooperatively are important to promoting children's healthy growth.

In this review of 27 studies, none of the studies investigated cooperation between nursery school teachers and nurses. The recently revised Child Health and Nursery School Guidelines and the Action Program seek provision of high-quality nursery services, stipulating the roles of each professional, including physicians on call, nurses, nutritionists, and cooking staff. Additional studies should be conducted to further explore appropriate collaboration while utilizing each professional's skills. Furthermore, the Child Health and Nursery School Guidelines also state the following about coordination and cooperation with other professional agencies and local communities: cooperation in general healthcare provision, coordination with the mother-child healthcare services, cooperation in dieting and nutrition programs, cooperation regarding care for children with disorders, cooperation regarding child-abuse prevention, cooperation in natural disasters, and cooperation with elementary schools. $^{14}$ However, given the current conditions of nursery schools where standards of nurse duties are not always clearly acknowledged and the fact that studies regarding cooperation with other agencies and local communities are limited, studies focusing on these areas are of urgent necessity.

Nursery school facilities with equipment are appropriate sites where efficient childrearing support to parents can be provided, and where professionals' collaborative services are expected. ${ }^{14}$ Previous studies of parents revealed their urgent requests for nursery schools to take care of sick children, including medica- 
tion administration, because many working mothers, who are an important part of the recent Japanese labor force, have diverse working schedules in this recession, and find it difficult to take days off from work. In addition, another need for nursery schools to serve as sites to provide support and advice on childrearing to parents has arisen, based on the recent tendency for parents to become isolated in dysfunctional community relationships. For parents who have anxiety and distress about childrearing, nursery school nurses play very important roles as social support providers. However, not all nursery school nurses have clinical experience as a pediatric nurse, and have few opportunities to attend training workshops and or consult with others, which may result in many nurses not being able to provide childrearing guidance and health activities with full confidence. Yano et al. ${ }^{20}$ points out that current nurse education programs do not have specific curricula for nursery school nurses, stating that "current nurse education fails to regard nursery schools as sites for health support provision, and does not clearly indicate the necessary knowledge and skills required of nursery school nurses," and further asserts the need to reexamine the curriculum of the Pediatric Nursing Sciences course. Taken together, these findings suggest the need to reconsider basic nursing education in order to build support systems where nursery school nurses can pursue healthcare tasks using their professional skills as well as fulfill the responsibilities expected of them.

\section{Conclusion}

This paper reviewed previous studies on the current conditions of nursery school nurses, and identified research trends in the past two decades and issues to be further investigated. While assigning nurses to nursery schools has not been smoothly implemented, nursery school nurses shoulder many social tasks, including supporting working mothers and caring for their children-precious "treasures" in a society where declining birthrates have accelerated - by maintaining their life, health, and safety. Nursery school nurses are expected to exercise their professional skills, but are often in situations where that is not fully possible. We hope the national and municipal governments, including the Ministry of Health, Labour and Welfare, will improve their policies regarding childrearing support.

\section{References}

1. Tamiaki GE ed, Amino TA, Sato NA, et al.
Development of the New Child Health and Nursery School Guidelines. Kenpakusha, 2009.

2. The Ministry of Health, Labour and Welfare. The Action Program for Quality Improvement of Nursery Schools ("Regarding Enforcement of the Child Health and Nursery School Guidelines" Issue Number: 0328001, Appendix 4), a material for the 1st council meeting of nursery school teacher training program, 2008.

3. Mitaka city. Almanac, Progress Report of the City, as of December of 2010. URL:http://www. city.mitaka.tokyo.jp/c-service/011/011301.html

4. Shinzansha ed. The Revised Child Welfare Act, Official Manuscript of the Revised Child Welfare Act for Minimum Standards, (Appendix) Comparisons of Old and New Articles of Minimum Standards (Partially revised on April 9, 1998), Details of the Supplementary Edition. Shinzansha Shuppan, 1998.

5. Akita KI, Amino TA, Ohba SA, et al. Commentary on the Child Health and Nursery School Guidelines, Hikarinokuni, 2008.

6. Statistical Association Health Foundation. Supplement to Health Indicator, Trends of the National Welfare, 2010; 57(11).

7. Takano AK and Nishimura SH ed. Nursery Care for Children During and Post Illness : Taking Care of Sick Children. Kitaôjishobô, 2009.

8. Endo IK. Cooperation in Nursery and Health Care: From a Perspective of Physicians on Call. Nursery and Health Care, 2005; 11(1): 90.

9. Gonda MI. Cooperation in Nursery and Health Care: Thoughts of Nurses. Nursery and Health Care, 2005 ; 11(1): 89.

10. Katsumata SU. Issues of Children at Risk in Family and Nursery School: Understanding and Response from Nurse Perspectives. Nursery and Health Care, 2006 ; 12(1) : 81-82.

11. Iguchi YU. Current Working Conditions of Nursery School Nurses: Support for Institutions without Nurse Assignment. Nursery and Health Care, 2006 ; 12(1): 92-93.

12. Nakayama MA. Child Illness and Medication Administration in Nursery Schools. Abstracts for the Annual Meeting of Japanese Society of Public Health, 2006; 64: 662.

13. Ariki $\mathrm{NO}$, Kimura $\mathrm{CH}$, Kiriyama $\mathrm{CH}$, et al. Roles of Nurses in Nursery Schools: Toward Children's Living Rhythm. Nursery and Health Care, 2007 ; 13(1) : 90.

14. Iimura NA, Emoto RI, Kawaguchi $\mathrm{CH}$, et al. Current Conditions of Cooperation between Nurses and Nursery School Teachers in Healthcare Facilities, Healthy Parents and Children, 21 Promotion Project, Activities for Children to Improve Emvironments of Hospitalization (Project of Cooperation among Nursery-Related Professions). The Journal of Japanese Society of Child Health Nursing, 2008 ; 17(2) : 66-72. 